\title{
Enasidenib Mesylate
}

National Cancer Institute

\section{Source}

National Cancer Institute. Enasidenib Mesylate. NCI Thesaurus. Code C137825.

The mesylate salt form of enasidenib, an orally available inhibitor of specific mutant forms of the mitochondrial enzyme isocitrate dehydrogenase type 2 (IDH2), with potential antineoplastic activity. Upon administration, enasidenib specifically inhibits various mutant forms of IDH2, including the IDH2 variants R140Q, R172S, and R172K, which inhibits the formation of 2-hydroxyg lutarate ( $2 \mathrm{HG}$ ). This may lead to both an induction of cellular differentiation and an inhibition of cellular proliferation in IDH2expressing tumor cells. IDH2, an enzyme in the citric acid cycle, is mutated in a variety of cancers; it initiates and drives cancer growth by blocking differentiation and the production of the oncometabolite $2 \mathrm{HG}$. 